\title{
Lateral eye movement and cognitive mode*
}

\author{
KATHERINE KOCEL, DAVID GALIN, ROBERT ORNSTEIN \\ and EDWARD L. MERRIN \\ Langley Porter Neuropsychiatric Institute, San Francisco, Calif. 94122
}

The direction of lateral eye movement elicited by reflective questions is strongly modified by the cognitive demands of the question; verbal and arithmetical questions elicit more movements to the right than do spatial and musical questions. This is consistent with the lateral specialization of the human brain for these cognitive processes. These results support the hypothesis that the direction of the lateral eye movement indicates the activation of the contralateral cerebral hemisphere.

People frequently look briefly to one side or the other prior to answering a question requiring a moment's consideration. It has been reported that the direction of this lateral eye movement is a reliable individual characteristic (Bakan, 1969; Bakan \& Svorad, 1969; Day, 1967; Duke, 1968). Those who look to the left on more than half the questions have been characterized as having higher resting EEG alpha rhythm, being more susceptible to hypnosis, having an internal focus of attention, a "soft" college major, and a lower mathematical score on the SAT (Bakan, 1969; Bakan \& Svorad, 1969; Bakan \& Shotland, 1969). Bakan (1969) has suggested that reflective lateral eye movements (LEMs) are an indication of the activation of the hemisphere of the brain contralateral to the direction of the eye movement. Hence, a left lateral eye movement would follow the activation of the right hemisphere. In this study, we attempted to confirm the previous reports that the direction of LEMs is a reliable characteristic of the individual, and additionally, to determine if LEMs are affected by the specific cognitive demands of the questions.

We suspected that the type of question asked might be important because clinical and laboratory evidence indicates that the two hemispheres of the brain are specialized for different cognitive functions (Bogen, 1969; Bogen \& Gordon, 1971; Corkin, 1965; Gazzaniga, 1970; Hécaen, 1962; Milner, 1965a, b; Sperry, Gazzaniga, \& Bogen, 1969; Zangwill, 1961). Patients with damage to the left hemisphere show a performance deficit on verbal and mathematical tasks, while spatial, pattern recognition, and musical functions suffer with right hemisphere

*We thank Douglas E. Eby for his help in collecting LEM data. This work was supported by Grant MH 19841 from the National institute of Mental Health and National Institute of Mental Health General Research Support Grant FR 05550. damage. Right temporal lobectomy severely impairs performance on visual and tactual mazes; equivalent lesions of the left temporal lobe cause little deficit on these tasks, but cause a variety of language dysfunctions (Corkin, 1965; Milner, 1965a, b). Studies of patients who had undergone complete separation of the two hemispheres by surgical section of the corpus callosum further confirm the lateral specialization of the brain (Bogen, 1969; Gazzaniga, 1970; Sperry, Gazzaniga, \& Bogen, 1969). In the "split-brain" patients, the left hemisphere is capable of speech, writing, and mathematics, but is severely limited on spatial and pattern recognition problems. The right hemisphere has a very restricted use of words and numbers but excels in complex tasks of spatial relations.

A review of the test materials used in the research defining hemispheric specialization suggested questions which would be expected to engage primanily either the left or the right hemisphere. In previous research, questions used to provoke LEMs were chosen without regard to hemispheric specialization. If a lateral eye movement results from the activation of one hemisphere, it might be expected that questions chosen to engage one hemisphere predominantly would result in LEMs to the contralateral direction. A question which engaged the right hemisphere (spatial, musical) should provoke a LEM to the left, and a question engaging the left hemisphere (verbal, mathematical) should result in a LEM to the right. It is hypothesized that more LEMs to the right will be made in response to "left hemisphere" questions than in response to "right hemisphere" questions.

\section{SUBJECTS AND PROCEDURE}

Twenty-nine volunteer Ss ( 16 males, 13 females) from 18 to 36 years of age were recruited for a study of "cognitive processing," with no mention of eye movements. The $\mathrm{S}$ was seated in a sound-attenuating chamber symmetrically draped with white curtains to insure a homogeneous visual field. A closed circuit TV camera with a close-up lens was centered in the $S$ 's visual field, $4 \frac{1 / 2}{\mathrm{f}}$ from him. The $S$ 's face filled a TV screen in the next room, from which his eye movements were recorded. Insiructions were read over an intercom. A question was not presented until the $\mathrm{S}$ faced the camera. The direction of the first LEM following each question was recorded, even though LEMs were sometimes made before the question was completely presented. Vertical eye movements including any lateral component were scored as LEMs. S's answers to the questions were not recorded.

Two groups of 20 questions were presented. Examples of verbal and mathematical questions intended to activate the left hemisphere are: (1) Solve the following arithmetic problem: $144 / 6 \times 4$. (2) Make up a sentence using two forms of the same verb. (3) Define the word "economics." Questions designed to engage the right hemisphere were spatial and musical; they included: (1) There is a profile of George Washington on a quarter. Which way does he face? (2) Imagine a rectangle. Divide it in half by drawing a line from the upper left-hand corner to the lower right. What two figures do you now have? $(3)$ Try to picture all the doors in your house and tell me how many door knobs there are. (4) Hum "Row, Row, Row, your Boat."

Each $S$ was presented with the "right" and "left" hemisphere questions in a counterbalanced order: RLLR or LRRL.

\section{RESULTS}

Table 1 presents the data. Both types of questions were equally effective in provoking LEMs; 20 verbal and mathematical questions ("left hemisphere") elicited an average of 18.3 LEMs, and 20 spatial and musical questions ("right hemisphere") elicited an average of 16.5 LEMs. The difference is not significant.

To test the effect of each type of question on the direction of LEM, we computed the percentage of right lateral eye movements for each set of questions for each S. Six Ss made less than 10 LEMs on one of the question sets and were omitted from this analysis. Twenty-two of the remaining 23 Ss made more right LEMs in response to "left hemisphere" questions than in response to "right hemisphere" questions, as was predicted. The mean percentage of right LEMs elicited by verbal and mathematical questions was $67.5 \%$, and the mean for the spatial and musical questions was $45.0 \%$. This 


\begin{tabular}{|c|c|c|c|c|c|c|}
\hline \multirow[b]{3}{*}{$\begin{array}{c}\text { S } \\
\text { Number }\end{array}$} & \multicolumn{3}{|c|}{$\begin{array}{c}\text { Spatial and Musical } \\
\text { Questions }\end{array}$} & \multicolumn{3}{|c|}{$\begin{array}{l}\text { Verbal and Mathematical } \\
\text { Questions }\end{array}$} \\
\hline & \multicolumn{3}{|c|}{ Right Hemisphere } & \multicolumn{3}{|c|}{ Left Hemisphere } \\
\hline & $\begin{array}{l}\text { Total } \\
\text { LEM }\end{array}$ & $\begin{array}{l}\text { Right } \\
\text { LEM }\end{array}$ & $\begin{array}{l}\text { Percent of } \\
\text { Right LEM }\end{array}$ & $\begin{array}{l}\text { Total } \\
\text { LEM }\end{array}$ & $\begin{array}{l}\text { Right } \\
\text { LEM }\end{array}$ & $\begin{array}{l}\text { Percent of } \\
\text { Right LEM }\end{array}$ \\
\hline $1-M$ & 17 & 3 & 17.7 & 17 & 6 & 35.3 \\
\hline $2-F$ & 18 & 7 & 38.9 & 20 & 16 & 80.0 \\
\hline $3-M$ & 17 & 7 & 41.2 & 19 & 12 & 63.2 \\
\hline $4-F$ & 17 & 7 & 41.2 & 18 & 17 & 94.4 \\
\hline $5-M$ & 11 & 6 & 54.6 & 17 & 15 & 88.2 \\
\hline $6-F$ & 18 & 11 & 61.9 & 18 & 17 & 94.4 \\
\hline $7-F$ & 20 & 8 & 40.0 & 19 & 11 & 57.9 \\
\hline $8-M$ & 16 & 6 & 37.5 & 18 & 14 & $\mathbf{7 7 . 8}$ \\
\hline $9 \cdot \mathbf{F}$ & 16 & 7 & 43.8 & 19 & 17 & 89.5 \\
\hline $10-F$ & 15 & 9 & 60.0 & 15 & 12 & 80.0 \\
\hline $11 \cdot M$ & 20 & 5 & 25.0 & 19 & 10 & 52.6 \\
\hline $12-F$ & 18 & 8 & 44.4 & 19 & 12 & 63.2 \\
\hline $13-M$ & 14 & 6 & 42.9 & 19 & 13 & 68.4 \\
\hline $14-F$ & 16 & 9 & 56.3 & 19 & 9 & 47.4 \\
\hline $15 \cdot M$ & 15 & 3 & 20.0 & 19 & 10 & 52.6 \\
\hline $16-\mathrm{M}$ & 14 & 10 & 71.4 & 16 & 12 & 75.0 \\
\hline $17-M$ & 18 & 15 & 83.3 & 16 & 15 & 93.8 \\
\hline $18-F$ & 17 & 5 & 29.4 & 19 & 9 & 47.4 \\
\hline $19-F$ & 20 & 10 & 50.0 & 19 & 14 & 73.7 \\
\hline $20-F$ & 14 & 11 & 78.6 & 20 & 16 & 80.0 \\
\hline $21-F$ & 19 & 6 & 31.6 & 19 & 13 & 68.4 \\
\hline $22-F$ & 16 & 5 & 31.3 & 18 & 6 & 33.3 \\
\hline $23-M$ & 14 & 5 & 35.7 & 19 & 7 & 36.8 \\
\hline Mean & 16.5 & 7.3 & 45.0 & 18.3 & 12.3 & 67.5 \\
\hline SD & 2.3 & 2.8 & 17.4 & 1.3 & 3.4 & 19.4 \\
\hline
\end{tabular}

sets of questions. Nevertheless, we were able to demonstrate two effects: (1) individual tendencies to look more toward one direction, and (2) strong modifications of these tendencies by the cognitive demands of the questions. Similar results have recently been obtained by $M$. Kinsbourne (personal communication).

\section{REFERENCES}

BAKAN, P. Hypnotizability, laterality of eye-movements and functional brain asymmetry. Perceptual \& Motor Skills, $1969,28,927-932$.

BAKAN, P., \& SHOTLAND, R. L. Lateral eye movement, reading speed, and visual attention. Psychonomic Science, 1969, 15, 93-94.

BAKAN, P., \& SVORAD, D. Resting EEG alpha and asymmetry of reflective eye movements. Nature, $1969,223,975-976$.

BOGEN, J. E. The other side of the brain: I, II, III. Bulletin of the Los Angeles Neurological Society, 1969, 34, 73-105, 135-162, 191-220.

BOGEN J. E \& GORDON, H. W. Musical tests for functional lateralization with intracarotid amobarbital. Nature, 1971, 230, 524-525.

CORKIN, S. Tactually-guided maze learning in man: Effects of unilateral cortical excisions and bilateral hippocampal lesions. Neuropsychologia, 1965,3 , 339-351.

DAY M. D. An eye-movement indicator of individual differences in the physiological organization of attentional processes and anxiety. Journal of Psychology, 1967, 66, 51-62.

difference is significant $[p<.01$, $\mathrm{T}=5, \mathrm{~N}=23$, Wilcoxon matched-pairs signed-ranks test (Siegel, 1956)].

To test the hypothesis that the direction of LEM is a reliable individual characteristic, we evaluated for each $S$ the distribution of direction of LEMs on both sets of questions combined. Nine of the 23 Ss had a distribution different from chance at $\mathrm{p}<.05$ by the binomial test (two-tailed; Siegel, 1956). Eight of these looked predominantly to the right, one to the left. The combined probability for the distributions of the whole group is $\mathrm{p}<.005$ (chi square $=$ 113.7 ) (Jones \& Fiske, 1953). Therefore, we can confirm previous reports that (at least some) individuals can be characterized as "right movers" or "left movers."

We then did a similar analysis of individuals' tendencies to show a preferred direction of LEM on each type of question. In response to "left hemisphere" questions, 9 of $23 \mathrm{Ss}$ had distributions significantly different from chance $(p<.05)$ by the binomial test. All were "right movers" on this set of questions and were, or tended to be, "right movers" overall. On the "right hemisphere" questions, only 4
Ss had distributions different from chance, and 3 out of 4 were "left movers" on this set of questions and were, or tended to be, "left movers" overall. The combined probability of the distributions for the group of "left hemisphere" questions is $\mathrm{p}<.005$, but only $p>.25$ on "right hemisphere" questions (chi square $=132.0$ and 56.7). This analysis suggests that if an individual has a tendency to move his eyes in one direction, this tendency is strongly modified by the cognitive demands of the questions.

\section{DISCUSSION}

Our questions were selected to make specific cognitive demands and were presented in blocks to emphasize the demand characteristics. Some of the questions used in previous studies have minimized constraints on the type of cognitive process which the $S$ might use to answer. For example, the question, "If you were President, how would you deal with the Vietnam situation?" (Bakan \& Svorad, 1969) might equally well be approached initially with verbal concepts or with a set of visual or kinesthetic images. This sort of question would be more likely to reveal an individual's tendency to look in one direction than would our
DUKE J D Lateral eye movement behavior. Journal of General Psychology, $1968,78,189-195$.

GAZZANIGA, M. S. The bisected brain New York: Appleton-Century-Crofts 1970 .

HÉCAEN, H. Clinical symptomatology in right and left hemispheric lesions. In $\mathrm{V}$. B. Mountcastle (Ed.), Interhemispheric relations and cerebral dominance. Baltimore: Johns Hopkins Press, 1962.

JONES, L. V., \& FISKE, D. W. Models for testing the significance of combined results. Psychological Bulletin, 1953, 50. 375-382.

MILNER, B. Brain mechanisms suggested by studies of temporal lobes. In F. L. Darley and C. H. Millikan (Eds.), Princeton conference on brain mechanisms underiying speech and language. New York: Grune \& Stratton, 1965a.

MILNER, B. Visually guided maze learning in man: Effects of bilateral, frontal, and unilateral cerebral lesions. Neuropsy chologia, 1965b, 3, 317-338.

SIEGEL, S. Non-parametric statistics. New York: McGraw-Hill, 1956.

SPERRY, R. W., GAZZANIGA, M. S., \& BOGEN, J E. Interhemispheric relationships: the neocortical commissures; syndromes of hemisphere disconnection. In P. S. Vilden and G. W. Bryn (Eds.), Handbook of clinical neurology. Vol. 4. Amsterdam: North Holland, 1969.

ZANGWILL, O. L. Asymmetry of cerebral function. In H. Garland (Ed.), Scientific aspects of neurology. London: Livingston, 1961. 